\title{
Scale effect in blockbuster research and development: The differences between production in Japanese Firms and in US/EU Firms
}

\author{
T. Miyashige $^{\text {a }}$ and A. Fujii ${ }^{\text {b }}$ \\ ${ }^{a}$ Advanced Courses of International Business, Toyama National College of Technology, Ebie-Neriya 1-2, \\ Imizu, Toyama, 933-0293 Japan \\ ${ }^{b}$ Faculty of Economics and Business Administration, The University of Kitakyushu, Kitagata 4-2-1, Kokura- \\ minamiku, Kitakyushu, Fukuoka, 802-8577 Japan \\ Email:miyasige@nc-toyama.ac.jp
}

\begin{abstract}
The purpose of this study is to empirically analyze the differences between blockbuster (big sales new drugs) production in Japanese firms and in US/EU firms. Many previous studies used the NCEs (New Chemical Entities) or patents as a measure of the performance of pharmaceutical R\&D. But most of the profit of the pharmaceutical companies is gained by small number of new drugs with big sales, called blockbusters. Thus, we focus on blockbuster research and development in this study.

The pharmaceutical R\&D can be divided into the research and the development processes. The research process is the process to seek a NCE candidate protected by the patent. On the other hand, the development process makes up one of the NCEs into a new drug. For this reason, we analyze not only the differences in research process but also the differences in development process.

The estimation results for Japanese firms are summarized as follows: The research process shows decreasing returns to R\&D investment scale, but the development process shows increasing returns. On the other hand, the estimation results for US/EU firms, larger than Japanese firms in their operating scale, are summarized as follows: The research process shows decreasing returns to R\&D investment scale, but the development process shows constant returns. From these estimation results, we find important differences between blockbuster production in Japanese firms and in US/EU firms. US/EU firms are lager than Japanese firms, but the blockbuster production in development process of US/EU firms is low. While the blockbuster production in research process of US/EU firms is similar to Japanese firms.
\end{abstract}

Keywords: $\quad$ blockbuster R\&D, Scale effect, Japanese Firms, US/EU Firms 
Miyashige and Fujii, Scale effect in blockbuster research and development: The differences between production in Japanese Firms and in US/EU Firms

\section{INTRODUCTION}

In this study, we will empirically analyze the differences between blockbuster (big sales new drugs) production in Japanese firms and in US/EU firms.

The most of the profit of the pharmaceutical companies is gained by small number of new drugs with big sales, called blockbusters. But many previous studies did not use the blockbuster as a measure of the performance of pharmaceutical R\&D.

Blockbusters will become the internal resource contributes to its competitive advantage by the 'valuerareness-inimitability-organization (VRIO)' framework based on the 'resource based view (RBV)' theory (Barney, 1991; Wernerfelt, 1984). Barney (1991) suggested such internal resource should have economic value, rareness and inimitability jointly.

Kranzler et al. (1995) and Boulton (2000) suggested the use of blockbuster (big sales new drugs) as a measure of effective internal resource in pharmaceutical industry, because it enables business organizations to satisfy VRIO criteria. Their suggestion emphasizes proprietary firms' profit motivation, and reveals that previous studies have shortcomings in the selection of target variable as described below.

Previous pharmaceutical R\&D studies are categorized into four groups as follows, using this suggested concept.

The first group is the empirical studies by Gambardella (1992), Henderson and Cockburn (1996), and Schwartzman (1976), which measured internal resource by the number of pharmaceutical patents. The second group is those by Graves and Langowitz (1993), Jensen (1987), and Odagiri and Murakami (1992), which used the number of new chemical entities (NCEs). These variables lack rareness and economic value except for inimitability.

The third group is by Comanor (1965), Schwartzman (1976), and Vernon and Gusen (1974), which used a combination of the number of NCEs and the sales amount. Explained variables in this group have both inimitability and economic value, but lack rareness.

The fourth group is by Cockburn and Henderson (2001), which used the number of approved new drugs. The explained variable has inimitability and limited economic value, but it lacks rareness.

Thus, we are able to overcome these shortcomings using blockbuster as an output measure. Moreover, if we take blockbuster as final output measure, the NCE candidate protected by the patent should be treated simply as intermediate inputs to the whole R\&D process. These two improvements can be made by estimating patent equation and subsequent blockbuster equation simultaneously.

A series of studies by Miyashige et al. (2007) and Fujii and Miyashige (2009), for example, has contributed in this context. Some of the studies were undertaken for US/EU area, and others were done for Japan area, the three major headquarter areas of pharmaceutical industry in the world. The purpose of this paper is to do a 'meta-analysis' of these studies to clarify the difference between each studies and characterize the factors behind it.

\section{RESEARCH AND DEVELOPMENT PROCESSES OF BLOCKBUSTER}

The pharmaceutical R\&D can be divided into the research and the development processes.

The research process is the process to determine a NCE candidate for development. A NCE candidate protected by the patent results from the research process. Each research project is carried out by a small unit of individual researchers, and these units seek different NCEs independently. The success of each individual research project depends highly on serendipity, rather than large R\&D investment. Further, the percentage of useful NCEs protected by the patent that shows immediate applicability to blockbuster is quite small.

The development process makes up one of the NCEs into a new drug. This process goes from the preclinical trial to the clinical trial, and then to the post marketing surveillance (PMS) after approval and release. In the development process, especially at the clinical trial and PMS, a vast amount of R\&D investment and many large organized activities are required. If the safety and effectiveness of the new drug cannot be confirmed 
Miyashige and Fujii, Scale effect in blockbuster research and development: The differences between production in Japanese Firms and in US/EU Firms

during PMS, the approval for such medicinal product will be cancelled. Therefore, a new drug that remains approved can be seen as a result of the development process. Small umber of new drugs with big sales, called blockbusters, contributes to the profit of pharmaceutical companies as described above.

In Japan, one of the largest pharmaceutical companies Takeda created many blockbusters by own research and development capability in the 1990s. But they began to buy research outcome from small ventures in the 2000s. Examples are not limited to this company, but many of other large Japanese companies including Astellas Pharma, Daiichi-Sankyo and Eisai seem to have changed their R\&D strategy from "develop what they found in their own research capability" to "develop what they buy from small ventures" to a certain extent.

In US/EU, one of the largest pharmaceutical companies Merck \& Co. created many blockbusters by own research and development capability until the mid 1990s. But they began to buy research outcome from small ventures since the mid 1990s. Examples are not limited to this company, but many of other large US/EU companies including Pfizer and Roche seem to have changed their R\&D strategy from "develop what they found in their own research capability" to "develop what they buy from small ventures" to a certain extent.

For this reason, we consider not only the differences in research process but also the differences in development process.

\section{COMMON MODEL}

A simultaneous equation model for pooled data with a count data equation has been used to estimate the relation between R\&D investment, patents which are research outcomes, and blockbusters which are profitability development outcomes. The model used in Miyashige et al. (2007) and Miyashige and Fujii (2010) is:

$$
\begin{aligned}
& \text { (1) } \log P A T_{i, t-1} \mid \mu_{i, t-1} \sim N\left(\mu_{i, t-1}, \sigma^{2}\right), \\
& \text { (2) } \mu_{i, t-1}=\alpha_{0}+\alpha_{R} \log R D_{i, t-1}, \\
& \text { (3) } \operatorname{Pr}\left(B B_{i, t}=b \mid \lambda_{i, t}\right)=\frac{\exp \left(-\lambda_{i, t}\right) \cdot \lambda_{i, t}{ }^{b}}{b !}, \\
& \text { (4) } \log \lambda_{i, t}=\beta_{0}+\beta_{P} \cdot \log P A T_{i, t-1}+\beta_{R} \cdot \log R D_{i, t},
\end{aligned}
$$

where $P A T$ is the number of patents newly acquired by the company; $B B$ is the number of blockbusters sold by the same company; $R D$ is the annual total R\&D investment of the company. The subscripts $i$ and $t$ denote firm and period respectively. $B B$ is assumed to have a Poisson distribution with mean $\lambda$ (equation (3)). Given the data for $P A T, B B$, and $R D$, the parameters $\left(\alpha_{0}, \alpha_{R}, \beta_{0}, \beta_{P}, \beta_{R}, \sigma\right)$ are estimated by the maximum likelihood estimation (MLE) method.

For equation (1), $P A T$ is assumed to have a log-normal distribution. Though $P A T$ is a count data by nature, the maximum value of $P A T$ is usually 100 or over so that it is too large to apply a conventional count data model such as a Poisson regression. Instead, a normal distribution for $\log P A T$ is adopted

For equation (2), $\log R D$ is a proxy variable for $\mathrm{R} \& \mathrm{D}$ investment for research process. In many previous studies the lagged values of $R D$ are jointly taken as explanatory variables. Unfortunately, their data has relatively short time-series for many firms and thus those authors instead focus on the scale aspect of the firm at the corresponding time period when the explained variable is observed.

Equation (3) depicts the count data nature of the number of blockbusters, with the mean given in equation (4). As explanatory variables of $B B$, both the $\log$ of the number of patent $(\log P A T)$ at the previous 
Miyashige and Fujii, Scale effect in blockbuster research and development: The differences between production in Japanese Firms and in US/EU Firms

period and $\log R D$ at the current period are employed, as indicated in equation (4). As is clear by the argument in the previous section, the pharmaceutical companies seek to turn their foregoing patents into profitable products. Therefore it is reasonable that the lagged value of $\log P A T$ is taken as an explanatory variable together with the development investment scale proxy $\log R D$ at the observed time period.

\section{ANALYSIS OF JAPANESE FIRMS}

\subsection{Data}

In Miyashige and Fujii (2010), data for Japanese firms were collected from several sources. For the number of blockbusters ( $B B$ ) was collected from Monthly Mix Magazine (Elsevier Japan, 1996-2009). Blockbusters with an annual sale exceeding 30 billion yen were examined. The $R \& D$ investment $(R D)$ in million yens and the number of patents ( $P A T$, international classification $\mathrm{A} 61 \mathrm{~K}$ in Japan) were obtained from DATABOOK (1996-2009) published by Japan Pharmaceutical Manufacturers Association (JPMA). After eliminating observations which lack necessary data, we obtained 134 observations for 22 Japanese pharmaceutical companies. Sample years range from 1995 to 2007. $R D$ is adjusted by GDP deflator. The descriptive statistics of their data is suggestive when they are compared with their EU/US counterparts discussed in Section 6. Here we show them in Table 1.

Table 1. Descriptive statistics for Japanese firms.

\begin{tabular}{ccccc} 
Variable & Mean & Std. Dev. & Min & Max \\
\hline$B B$ & 0.925 & 1.115 & 0 & 5 \\
$\log P A T$ & 3.486 & 0.780 & 1.792 & 5.328 \\
$\log R D$ & 10.330 & 0.757 & 8.407 & 11.938
\end{tabular}

*Number of Observation is 134.

\subsection{Estimation Result}

Table 2 recites the estimation result of the equations (1) through (4) in Miyashige and Fujii (2010) for later use. The investment scale effect parameter in the blockbuster equation, $\beta_{R}$, is estimated to be 1.404 with the standard error 0.273 . These figures show increasing returns to investment scale in the production of $B B$. On the other hand, $\alpha_{R}$, the investment scale effect parameter in the patent equation, show decreasing returns to investment scale. This result emphasizes the productivity of Japanese pharmaceutical research process is quite different from that of development process in terms of investment scale.

Table 2. Result of MLE for Japanese firms.

\begin{tabular}{ccccc} 
Parameter & Estimate & Std. Err. & t-statistic & P-value \\
\hline$\alpha_{0}$ & -3.580 & 0.836 & -4.284 & 0.000 \\
$\alpha_{R}$ & 0.687 & 0.081 & 8.431 & 0.000 \\
$\beta_{0}$ & -14.091 & 2.446 & -5.760 & 0.000 \\
$\beta_{P}$ & -0.250 & 0.243 & -1.030 & 0.303 \\
$\beta_{R}$ & 1.404 & 0.273 & 5.143 & 0.000 \\
$\sigma^{-1}$ & 1.694 & 0.108 & 15.682 & 0.000 \\
$\begin{array}{c}\text { Log } \\
\text { likelihood }\end{array}$ & -259.000 & & &
\end{tabular}

The parameter $\beta_{P}$ reflects how much the development process is affected by the outcome of research process. The estimate is -0.250 and is not statistically significant. This result implies no quantitative correlation between the outcomes of research and development processes in spite of the qualitative 
Miyashige and Fujii, Scale effect in blockbuster research and development: The differences between production in Japanese Firms and in US/EU Firms

connection between the two. The empirical independence of patents and blockbuster, together with the great difference in the investment effects on patents and blockbusters, implies the essential difference in the research and the development processes in the Japanese pharmaceutical R\&D.

\section{ANALYSIS OF US/EU FIRMS}

\subsection{Data}

In Miyashige et al. (2007), data for US/EU firms were collected from several sources. For the number of blockbusters $(B B)$, the source is as follows: Data for years 1990 to 1995 were from various issues of Scrip Magazine (Informa in U.K., 1990 to 1995); Data for 1996 was from Pharma Future Magazine (UTO-BRAIN in Japan, 1996); No data could be obtained for 1997; Data for 1998 was from Pharma Japan Handbook (Yakugyo Jihosha in Japan, 1998) and were available for U.S. firms only; Data for 1999 and 2000 were from a press release by Yoshikawa Pharma Institute in Japan (dated May 28, 2001); Data for years 2001 to 2003 were from Monthly Mix Magazine (Elsevier Japan, issues in 2003 and 2004). Blockbusters with an annual sale exceeding one billion U.S. dollars were examined.

The R\&D investment ( $R D)$ and the number of patents ( $P A T$, international classification A61K in Japan) were obtained from DATABOOK (1992-2005) published by Japan Pharmaceutical Manufacturers Association (JPMA). The $R D$ data were converted to U.S. dollars by the Purchasing Power Parity (PPP) issued by Organisation for Economic Co-operation and Development (OECD), and is expressed in million U.S. dollars.

After eliminating observations which lack necessary data, they obtained 136 observations for 29 US/EU pharmaceutical companies. Sample years range from 1992 to 2003 except for 1997. The descriptive statistics of the data described above are shown in Table 3.

Table 3. Descriptive statistics for US/EU firms.

\begin{tabular}{ccccc} 
Variable & Mean & Std. Dev. & Min & Max \\
\hline BB & 1.926 & 1.961 & 0.000 & 10.000 \\
$\log P A T$ & 3.717 & 0.861 & 1.609 & 6.205 \\
$\log R D$ & 7.337 & 0.596 & 6.122 & 8.872
\end{tabular}

*Number of Observation is 136.

\subsection{Estimation Result}

Table 4 shows the estimation result of the equations (1) through (4). The scale effect parameter in the blockbuster equation, $\beta_{R}$, is estimated to be 0.903 with the standard error 0.184 . These figures show constant returns to investment scale in the production of $B B$. On the other hand, $\alpha_{R}$, the scale effect parameter in the patent equation, show decreasing returns to investment scale. This result emphasizes the

Table 4. Result of MLE for US/EU firms.

\begin{tabular}{ccccc} 
Parameter & Estimate & Std. Err. & t-statistic & P-value \\
\hline$\alpha_{0}$ & -1.119 & 0.888 & -1.260 & 0.208 \\
$\alpha_{R}$ & 0.667 & 0.119 & 5.597 & 0.000 \\
$\beta_{0}$ & -7.591 & 1.283 & -5.919 & 0.000 \\
$\beta_{P}$ & 0.361 & 0.123 & 2.944 & 0.003 \\
$\beta_{R}$ & 0.903 & 0.184 & 4.897 & 0.000 \\
$\sigma^{-1}$ & 1.321 & 0.087 & 15.269 & 0.000. \\
$\begin{array}{c}\text { Log } \\
\text { likelihood }\end{array}$ & -343.715 & & &
\end{tabular}


Miyashige and Fujii, Scale effect in blockbuster research and development: The differences between production in Japanese Firms and in US/EU Firms

productivity of US/EU pharmaceutical research process is quite different from that of development process in terms of investment scale.

The parameter $\beta_{P}$ reflects how much the development process is affected by the output of research process. The estimate is 0.361 , which means $1 \%$ increase in the number of patents brings $0.361 \%$ increase in the number of blockbusters. This elasticity is definitely less than the scale elasticity $\beta_{R}$. Using the sample means of $\log P A T$ and $B B$ (3.717 and 1.926 respectively), we roughly calculate in numerical term, 59 $(=\exp (3.717) / 1.926 / 0.361)$ newly approved patents are required to issue one additional blockbuster.

\section{DISCUSSION AND CONCLUSIONS}

Table 5 shows the differences between blockbuster (big sales new drugs) production in Japanese firms and in US/EU firms.

Our result of simultaneous estimation of patent and blockbuster equations on Japanese firms are summarized as follows: (i) The research process shows decreasing returns to R\&D investment scale; (ii) The development process shows increasing returns to $R \& D$ investment scale; (iii) The empirical effect of patents on the number of blockbuster is not significant.

On the other hand, Our result of simultaneous estimation of patent and blockbuster equations on US/EU firms are summarized as follows: (i) The research process shows decreasing returns to R\&D investment scale; (ii) The development process shows constant returns to R\&D investment scale; (iii) The empirical effect of patents on the number of blockbuster is small.

From these estimation results, we find two important differences between blockbuster production in Japanese firms and in US/EU firms. First, US/EU firms are lager than Japanese firms, but the blockbuster production in development process of US/EU firms $\left(\beta_{R}: 0.903\right)$ is low rather than Japanese firms $\left(\beta_{R}: 1.404\right)$. While the blockbuster production in research process of US/EU firms( $\left.\alpha_{R}: 0.667\right)$ is similar to Japanese firms $\left(\alpha_{R}\right.$ :0.687). Second, Japanese firms $\left(\beta_{P}\right.$ :not significant) could not research NCE candidate of blockbuster in house while US/EU firms $\left(\beta_{P}\right.$ :Significant, but weak) could research a few NCE candidate of blockbuster in house.

This seems to have two important implications. First, the productivity or the production structure of pharmaceutical research process is universal in the world. This is partly explained by the fact that the lisencein tendency began to prevail in the three regions in 1990's. Second, since the operation scale of firms in Japanese sample is smaller than that of US/EU samples, growth of the scale economy of development process in Japan may stop after Japanese firms become as large as those of US/EU firms. This implies more flexible functional forms such as trans-log is suitable for those samples with wider range of operating scales.

Table 5. Summary of Results.

\begin{tabular}{llll} 
& & Japanese & US/EU \\
\hline Returns & Research Process & Decreasing & Decreasing \\
\cline { 2 - 4 } to & Development Process & Increasing & Constant \\
\cline { 2 - 4 } investment Scale & Scale Effect Inequality & $\mathrm{R}(0.687)<\mathrm{D}(1.404)$ & $\mathrm{R}(0.667)<\mathrm{D}(0.903)$ \\
\hline Quantitative Connection between R\&D & Not significant & Significant, but weak $(0.361)$ \\
\hline
\end{tabular}

\section{REFERENCES}

Abdelmoula, M. and G. Bresson (2008). Spatial and technological spillovers in European patenting activities: A dynamic count panel data model. Annals of Economics and Statistics 87/88, 167-194.

Al-Osh, M. A. and A. A. Alzaid (1987). First-order integer valued autoregressive (INAR(1)) process. Journal of Time Series Analysis 8, 261-275. 
Miyashige and Fujii, Scale effect in blockbuster research and development: The differences between production in Japanese Firms and in US/EU Firms

Barney, J. B. (1991). Firm resources and sustained competitive advantage. Journal of Management 17, 99120.

Blundell, R., R. Griffith, and J. V. Reenen (1995). Dynamic count data models of technological innovation. The Economic Journal 105(429), 333-344.

Blundell, R., R. Griffith, and F. Windmeijer (2002). Individual effects and dynamics in count data models. Journal of Econometrics 108, 113-131.

Boulton, W. R. (2000). Consolidations and alliances: challenges to US pharmaceutical leadership. Journal of Health Care and Society 10(1), 73-111.

Cockburn, I. M. and R. M. Henderson (2001). Scale and scope in drug development: Unpacking the advantages of size in pharmaceutical research. Journal of Health Economics 20, 1033-1057.

Comanor, W. S. (1965). Research and technical change in the pharmaceutical industry. Review of Economics and Statistics 47, 182-190.

Crépon, B. and E. Duguet (1997). Estimating the innovation function from patent numbers: GMM on count panel data. Journal of Applied Econometrics 12, 243-263.

Fujii, A. and T. Miyashige (2009). Scale economies of pharmaceutical patent and blockbuster R\&D with possible endogeneity and dynamics. In R. S. Anderssen, R. Braddock, and L. Newham (Eds.), 18th World IMACS Congress and MODSIM09 International Congress on Modelling and Simulation, pp. 1113-1118. Modelling and Simulation Society of Australia and New Zealand and International Association for Mathematics and Computers in Simulation.

Gambardella, A. (1992). Competitive advantages from in-house scientific research: The US pharmaceutical industry in the 1980s. Research Policy 2, 391-407.

Graves, S. B. and N. S. Langowitz (1993). Innovative productivity and returns to scale in the pharmaceutical industry. Strategic Management Journal 14, 593-605.

Henderson, R. and I. Cockburn (1996). Scale, scope and spillovers: the determinants of research productivity in drug discovery. RAND Journal of Economics 27, 32-59.

Jensen, E. J. (1987). Research expenditures and the discovery of new drugs. Journal of Industrial Economics $36,83-95$.

Kranzler, J., D. Taylor and F. Weber (1995). Going for the gold: rules for a new game in drug development. The McKinsey Quarterly 5, 70-88..

Miyashige, T. (2008). Analysis of the "effective" R\&D that contributes profit: decomposition into research and development processes ("Shueki Ni Koken Suru Kenkyukaihatsuseika Ni Oyobosu Kenkyukaihatsutoshikoka No Kenkyu” in Japanese). Ph. D. thesis, Kanazawa University, The Graduate School of Natural Science and Technology.

Miyashige, T. and A. Fujii (2010). Are research and development processes independent in the Japanese pharmaceutical R\&D? In IIIS Electronic Proceedings, pp. 245-249. The 14thWorld Multi-Conference on Systemics, Cybernetics and Informations (WMSCI) 2010.

Miyashige, T., A. Fujii, and K. Kimura (2007). Are research and development processes independent in the pharmaceutical R\&D? In L. Oxley and D. Kulasiri (Eds.), MODSIM 2007 International Congress on Modelling and Simulation, pp. 74-80. Modelling and Simulation Society of Australia and New Zealand.

Montalvo, J. G. (1997). GMM estimation of count-panel-data models with fixed effects and predetermined instruments. Journal of Business and Economic Statistics 15(1), 82-89.

Odagiri, H. and N. Murakami (1992). Private and quasi-social rates of return on pharmaceutical R\&D in Japan. Research Policy 21, 335-345.

Schwartzman, D. (1976). Innovation in the Pharmaceutical Industry. Baltimore: Johns Hopkins University Press.

Vernon, J. M. and P. Gusen (1974). Technical change and firm size: the pharmaceutical industry. Review of Economics and Statistics 56, 294-302.

Wernerfelt, B. (1984). A resource-based view of the firms. Strategic Management Journal 5, 171-180. 